\title{
Lindonéia, Clandestinas e a prosa anônima das ruas: conversações entre arte, jornal e paisagem urbano-cultural
}

\author{
Mylène Goudet
}

Resumo: Os processos civilizatórios da América Latina se deram, e ainda se dão, de modos múltiplos, nunca completos e sempre aptos a incorporar textos exógenos. Por isso é necessário indisciplinar as fronteiras dos saberes, para nos relacionarmos com sua diversidade cultural (Martín-Barbero). Isso quer dizer que, no continente, os textos da cultura escapam às categorizações estanques e, quando postos em relação, acabam por intercambiar elementos de uma série cultural para outra (Pinheiro), produzindo alargamentos dialógicos entre suas fronteiras (Lotman). À luz desses conceitos, o artigo retoma experiências artísticas realizadas no Rio de Janeiro nas décadas de 1960 e 1970, por Rubens Gerchman e Antonio Manuel. Algumas obras desses artistas serão abordadas como arranjos expressivos inéditos entre séries culturais - o jornal, as artes plásticas e a paisagem urbano-cultural. Nessas experimentações, não podemos deixar de considerar o contexto da ditadura no Brasil, presente nas obras por meio de poéticas pouco óbvias, relacionadas com o cotidiano anônimo das ruas. Já o jornal impresso será tomado como objeto relacional que, no transbordamento de seus códigos próprios, abre-se para possibilidades de novas conexões e dobras de sistemas sobre outros sistemas - oralidade sobre o texto, da música sobre a poesia, do texto sobre a imagem, das artes gráficas sobre a música etc.

Palavras-chave: arte; jornal; cidade; Antonio Manuel; Lindonéia.

Abstract: Lindonéia, Clandestinas and the anonymous prose of the streets: conversations between art, newspaper and the urban-cultural landscape - The civilizatory processes in Latin America have occurred, and still do, in a multitude of forms, never complete as a whole, and always willing to incorporate exogenous texts. Therefore, it is necessary to loosen the disciplinary frontiers of the many knowledges in order for us to relate to the cultural diversity (MartínBarbero). In this sense, in the continent, the texts in-culture don't and can't fit the watertight categories and, when brought into comparison with other texts, ultimately exchange elements of a cultural universe to another (Pinheiro), enlarging the dialogic frontiers between them. (Lotman). In the light of those concepts, this article recaptures artistic experiments carried out 
in Rio de Janeiro in the 1960's and 1970's by Rubens Gerchman and Antonio Manuel. Some of the works by these artists are to be approached as unprecedented expressive arrangements between cultural series: The newspaper, arts and the cultural-urban landscape. In these experiments, the context of Brazil's dictatorship at the time cannot go unmentioned, as it is present in the works through their subtle poetry, related with the anonymity of the everyday life in the streets. As for the newspaper, it shall be taken as a relational object that, in the overflowing of its own set of codes, opens itself to the possibility of new connections and folds of systems over other systems - orality over text, music over poetry, text over image, graphic arts over music, etc.

Keywords: art; newspaper; city; Antonio Manuel; Lindonéia.

\author{
Um poeta desfolha a bandeira \\ E a manhã tropical se inicia \\ Resplandente, cadente, fagueira \\ Num calor girassol com alegria \\ Na geléia geral brasileira \\ Que o Jornal do Brasil anuncia [...] \\ Torquato Neto ${ }^{1}$
}

Martín-Barbero (2004, p. 13-19) explica que na América Latina é necessário indisciplinar as fronteiras dos saberes para podermos nos relacionar com sua diversidade de processos culturais. O autor diz ainda que o modelo de uma totalidade, unificada pela solda do antagonismo, não nos serve como chave relacional. Mas essa afirmação passa longe do caos como formulador de cultura no continente, pois, aqui, as articulações entre os diversos textos culturais são coesas e variadas, não aleatórias. Contudo, mesmo que estas articulações sejam fortes, os pontos conectivos (ou a solda) são fracos (LOTMAN, 2002, p. 100-102). Isso se dá porque os textos culturais não fidelizam com nenhuma tradição unívoca e hierárquica e estarão sempre prontos para se desgarrar de uns para esposar outros, criando assim, incessantemente, novos textos.

Por isso, ao tomarmos o jornal como objeto relacional, articulado nas relações entre mídia impressa, arte e realidade urbano-cultural, nos interessará muito pouco especular sobre os códigos internos próprios de cada um dos sistemas envolvidos (ou se um dos sistemas tem primazia sobre os outros) e nos será muito mais proveitoso fazer uma leitura das relações entre eles, observando de que forma são coordenadas suas singularidades a partir da ideia de mobilidade cultural apontada por Martín-Barbero e Lotman, destacada no parágrafo anterior. Sobre essa capacidade compositiva entre códigos diversos, Amálio Pinheiro esclarece que

Ganham primazia as interações produtivas entre os modos de estruturação gráfico-visual do jornal impresso e os ritmos e códigos espaciais e temporais das cidades. Somente uma análise dos nexos entre os modos de construção do jornal

1 Trecho do poema intitulado Geléia Geral. 
(diagramação, crônica etc.) e a formação das séries urbano-culturais no continente (espaços, ritmos e códigos que tendem a engastar linguagens e materiais para fora dos limites textuais) pode dar conta das modificações e diferenças que a partir do jornal impresso são reassimiladas por outros meios. (PINHEIRO, 2013, p. 45).

O jornal impresso na América Latina, segundo Pinheiro (2015, p. 45-50), é estruturalmente contraditório porque, ao mesmo tempo em que incorre na tarefa de homogeneizar e globalizar os discursos, acaba por dar passagem, mesmo sem querer, à variação e instabilidades do manancial dos objetos da cultura - bichos, natureza, palavras, utensílios, crendices. Isso porque os saberes anônimos estão fragmentados e embaralhados no cotidiano do continente - nos modos de falar, cantar, dançar, vestir, comer, morar, rezar etc. São vestígios das muitas culturas que desembarcaram (e ainda desembarcam) por aqui. Por sorte nosso processo civilizatório ocorre assim, múltiplo, descentralizado e fragmentário, nunca completo e sempre apto a incorporar outros textos.

Isso não significa, no entanto, que esses desembarques se deem tranquilamente. As disputas por poder e centralidade são constantes, talvez ontológicas, mas jamais nos resumiram a times binários - de conquistadores e de conquistados, do centro e da periferia, do erudito e do iletrado, e assim por diante. Tal formação, ainda em curso, é que impede a aderência completa da cultura aos discursos unificadores e totalitários, ainda que tais discursos abundem e se imponham - "discursos clássicos, eclesiásticos, tecnocapitalistas [...]" (PINHEIRO, 2013, p. 17) - de tempos em tempos, tentando formatar nossa assimetria compositiva.

Nossas fronteiras são naturalmente bilíngues (ou poliglotas) e, ao invés de separar, abrem brechas para que se dê o traspassamento de culturas marginais nos discursos oficiais, não por concorrência ou oposição, mas por composição complexa, gerando novos sentidos (LOTMAN, 1996, p. 87). Por isso é dado como certo que o latino-americano tenha um alto pendor tradutório e que se aproprie de textos alheios, mesmo que de forma inconsciente ou até indesejada. Parece que nos embates fronteiriços entre séries culturais é que mais afloram discursos alternativos que acolhem, como diferenciação, "o devir relacional, a absorção e tradução do outro como variação inclusiva [...]" (PINHEIRO, 2013, p. 17).

\section{O contexto do jornal para Rubens Gerchman e Antonio Manuel}

No segundo semestre de 2016, foi inaugurada, na Pinacoteca do Estado de São Paulo, a exposição de longa duração intitulada Vanguarda Brasileira nos anos de 1960 - Coleção Roger Wright. Num primeiro olhar, a exposição poderia ser qualificada como um recolhido da Arte Pop nacional por sua plástica, materiais, técnicas e cores, pela simplificação formal e referência às histórias em quadrinhos etc. Encontramos ali obras confeccionadas com materiais baratos que desafiam a conservação e a durabilidade 
das peças. Em contrapartida à fragilidade material, a tensão que imanta o conjunto das obras se dá, em parte, por conter um recorte temporal coincidente com a ditadura no Brasil, o que não é pouco relevante. Mas o que a exposição termina por revelar são particularidades da arte brasileira, seus modos de produzir uma discussão estética naquele contexto político, social e cultural, complicando seu enquadramento automático na Arte Pop.

Aqueles eram tempos analógicos e os noticiários ocupavam um espaço considerável no cotidiano das pessoas, principalmente o jornal impresso. Até que a ditadura fechasse definitivamente o cerco sobre as tribunas, o jornal era de grande relevância políticosocial. Artistas como Rubens Gerchman (1942-2008) e Antônio Manuel (1947), presentes na exposição em questão, tomaram a mídia impressa e seus processos de produção como material artístico.

Estes trabalhos nasceram da minha paixão pelo jornal como meio para captar a realidade imediata, tornar possível a criação poética e sobretudo a ideia de síntese entre o verbal e o visual contida no veículo. A maneira como os jornais são expostos nas bancas, o tipo de diagramação e paginação, com aquele apelo poético, dramático serviu de material para a elaboração dos meus trabalhos poemas visuais, que a princípio eram desenvolvidos no ateliê e depois realizados nas próprias oficinas de jornais junto ao barulho constante da redação e da rotativa. Tudo ali era criação, a transformação do vivido em algo gráfico-visual, com toda a carga desse vivido. Um ruído dinâmico que imprimia assim uma força viva ao trabalho. (ANTÔNIO MANUEL apud BUENO, 2010, p. 43).

Rubens Gerchman também era um assíduo leitor de jornal, extraía das páginas as histórias menores, sem importância, relacionadas com o cotidiano das ruas como inspiração para suas obras. No documentário Ver Ouvir, de 1966², o artista se posiciona em frente a uma banca de jornais de uma rua movimentada do Rio de Janeiro e declara, olhando para a câmera do diretor Antonio Carlos Fontoura, seu nome, altura, idade na ocasião 24 anos - e sua profissão, pintor; e segue dizendo: "Leio muito jornal. É onde recolho a maior parte do meu material de trabalho. Abro o jornal e dou de cara com a história de João, que fez o impossível para virar manchete, para deixar de ser um desconhecido ou um número de carteira de identidade".

Tomaremos algumas obras desses dois artistas que convergem na habilidade em transitar entre o jornal e a paisagem urbana, intrometendo elementos contra-hegemônicos em narrativas normalmente lineares, seja no resultado formal ou nas metodologias de ação. Eles são relevantes pela rebeldia com que parasitaram meios massivos de comunicação, não para produzir arte-panfletária, mas inventando estéticas de diálogo com o vozerio anônimo da cidade. Na incorporação e tradução de elementos do jornal, o "espaço das páginas volta-se para o espaço das ruas, e vice-versa, fomentando modos de comunicação e leitura interno-externos." (PINHEIRO, 2013, p. 10).

2 Transcrição de trecho do vídeo Ver Ouvir. 


\section{Lindonéia, paisagem de um amor impossível}

Lindonéia é uma canção composta por Caetano Veloso e Gilberto Gil, originalmente interpretada por Nara Leão, que faz parte do aclamado álbum Tropicália ou panis et circenses, lançado em agosto de 1968, quando o cenário repressivo da ditadura brasileira coexistiu com a efervescência artística, na qual figuraram personalidades como Hélio Oiticica, Glauber Rocha, José Celso Martinez Corrêa, Caetano Veloso, Gilberto Gil, Torquato Neto, entre tantos outros.

Gil, ao criar a melodia para a canção, incorpora habilmente elementos rítmicos do bolero, gênero musical assimilado por todas as classes sociais do Brasil, geralmente associado às histórias de amores melancólicos, dolorosos e mal correspondidos. Ao apropriar-se de sua carga subjetiva e emocional, a canção amplificou seus significados e, por consequência, se tornou mais complexa.

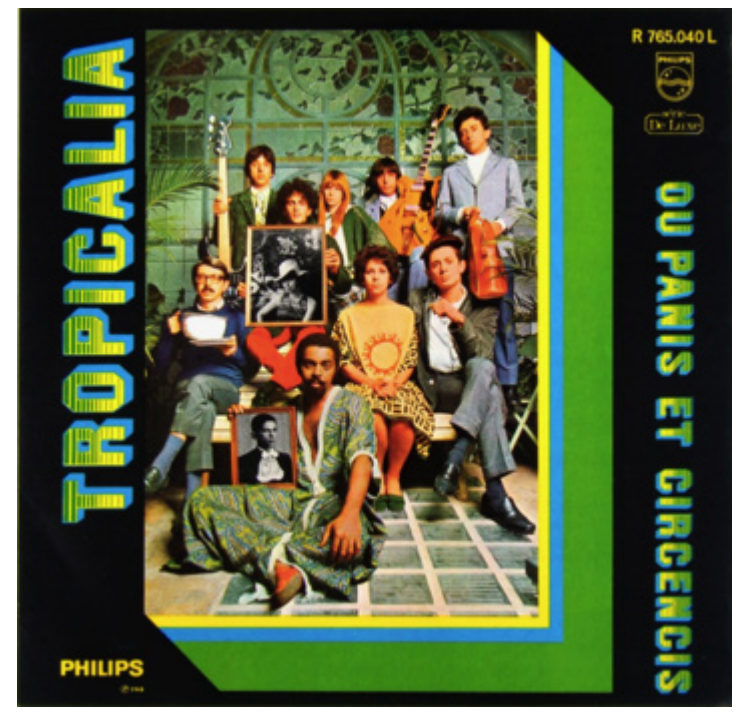

Fig. 1. Capa do disco de 1968, realizada por Rubens Gerchman.

A música fala de uma mulher cujo nome, Lindonéia, contém a paisagem cultural anônima e desvalida do Rio de Janeiro da época. Uma ínfima partícula, -néia, é portadora de incontestável cafonice lírica e inconsciente, que continua ressoando nos recantos mais escondidos dos nossos preconceitos. Lindonéia era pobre e mulata, presumida na efemeridade de uma foto mal impressa num jornal de notícias populares.

Lindonéia, cor parda

Fruta na feira 
Lindonéia solteira

Lindonéia, domingo

Segunda-feira

Nara Leão segue cantando a história dessa mulher, possivelmente vítima de um crime passional, tendo como pano de fundo a feira de rua e, mesmo denunciando a ostensiva presença da repressão policial, faz imperativa a poesia de seu anonimato.

\author{
Lindonéia \\ Na frente do espelho \\ Sem que ninguém a visse \\ Miss \\ Linda, feia \\ Lindonéia desaparecida \\ Despedaçados \\ Atropelados \\ Cachorros mortos nas ruas \\ Policiais vigiando \\ O sol batendo nas frutas \\ Sangrando \\ Oh, meu amor \\ A solidão vai me matar de dor
}

Na sua ambiguidade, a música alcança maior precisão poética. Seu jogo movediço traçou um retrato daquela sociedade brasileira: lírica, violenta, complexa e inconclusa. Lindonéia fricciona a repressão com amores anônimos, gente invisível com classe média alienada... e a cidade pulsando, a feira, as frutas, o sangue, a igreja.

Mas o brilhantismo da canção deriva de um diálogo anterior, entabulado entre artes plásticas, o jornal e a música, no deslizamento das fronteiras e especificidades formais de cada um desses campos comunicacionais. Haroldo de Campos (apud MORENO, 1979 , p. 304) nos conta que Gil e Caetano utilizaram a metalinguagem musical como crítica ao que existia na época, combinando palavra e som de modo similar à prática medieval chamada melopeia, "[...] revertendo para a oralidade as técnicas de uma poesia partitural e tipográfica". Essa característica compositiva só confirma a hipótese inicial deste artigo, que afirma a possibilidade de que, na América Latina, campos diversos da cultura aproveitem-se mutuamente por pertencerem a uma mesma articulação, transbordando qualquer categorização estanque, tal como gênero, estilo ou época.

A canção surge da visita de Nara Leão, em 1966, ao atelier de Gerchman. Ali ela conhece um quadro intitulado Lindonéia, a Gioconda do Subúrbio. O próprio artista narra, no programa televisivo Mundo da Arte - SESC TV, a história deste encontro. 
Quando a cantora se deparou com a obra, desejou comprá-la imediatamente, mas o artista não quis vendê-la por motivos pessoais. Nara Leão telefona para Caetano Veloso e descreve a obra a ele. Com base nessa descrição telefônica feita pela cantora, nasce a letra de Caetano, em seguida musicada por Gilberto Gil.

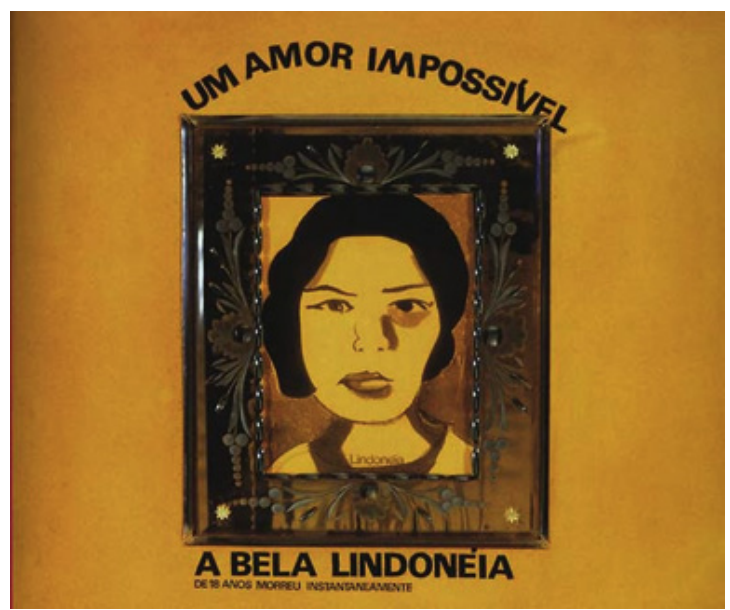

Fig. 2. Lindonéia, a Gioconda do Subúrbio (1966). Coleção Gilberto Chateaubriand, MAM Rio.

Lindonéia figura entre as obras de Gerchman inspiradas nas formas gráfico-visuais do jornal impresso, especialmente os de notícias populares. Portanto a simplicidade dos seus traços é proposital e não simplória. Observemos o rico palimpsesto de referências que o artista constelou nesta obra. O impacto visual de sua figura é imediato, como na publicidade. Seu rosto é pintado com traços fortes e poucas cores chapadas. O artista usufrui do campo simbólico popular, mas atualizado pela conexão inesperada de elementos kitsch com a linguagem das artes gráficas e do jornal.

O rosto de Lindonéia parece ter saído de um jornal sensacionalista e, reforçado por uma legenda pintada sobre a tela, em forma de manchete - "Um amor impossível: a bela Lindonéia de 18 anos morreu instantaneamente" - que acusa a violência do acontecimento retirando momentaneamente a moça do anonimato. Mas não é definitiva sua morte por amor, se considerado o contexto da ditadura, dos crimes políticos. Assim como na música homônima de Caetano, há uma presença ambígua da polícia. Lindonéia, vítima ou acusada?

Gerchman é hábil na construção da paródia, que desde o título - Lindonéia, a Gioconda do Subúrbio - atrita duas obras de arte irreconciliáveis e suas infinitamente distantes representações femininas: Lindonéia e Monalisa. Ao intitular o quadro desta maneira, Gerchman se apropria da universalidade de Leonardo Da Vinci, cuja Gioconda está instalada no imaginário de significativa parcela da humanidade, para ascender Lindonéia, a anônima, à categoria de musa. O artista, que pintava concursos de miss e cenas de fotonovela, trava um diálogo paródico com o Renascimento. É o universo brega, 
provisório e particular do Brasil que entra em cena, em igualdade artificiosa com a arte canônica. Se La Gioconda sorri misteriosa, Lindonéia exibe a carnalidade de seus lábios de mulata. E se a paisagem da Gioconda se evapora com o sfumatto de Da Vinci, a de Lindonéia está precisamente delimitada por um porta-retrato de vidro bisotado, que narra com exatidão sua geografia subjetiva - mulher, anônima, violentada, parda, pobre e do subúrbio.

\section{Antonio Manuel e as Clandestinas, a mimese escandalosa}

Para me inspirar

Abro a janela

Como um jornal

Oswald de Andrade $^{3}$

Antonio Manuel (1947), artista contemporâneo de Gerchman, também faz do jornal impresso um meio para criação poética, daí que parte de sua obra consistiu em produzir desvios intencionais nas capas do jornal carioca $O \mathrm{Dia}^{4}$, de tal forma que sua intervenção se ajustasse na página sem modificar a diagramação costumeira, enquanto que o texto da manchete e das notícias que ele fabricava eram distintos dos conteúdos do jornal. Numa primeira vista, sua intervenção passava desavisada. Estas obras foram chamadas de Clandestinas, uma série de 10 capas reproduzidas por ele às centenas, no início dos anos 1970. O próprio artista conta que

Fazia as matérias em casa, ia para a oficina e batia o texto à máquina, como se fosse funcionário do jornal. Três a dez operários trabalhavam comigo. Algumas vezes o diagramador tinha de se virar para encaixar minhas "notícias". Discutíamos até a proporção das letras para que o texto coubesse nas páginas. O grande barato era que o meu jornal ficasse exatamente igual ao original, acrescido apenas dos elementos poéticos que criava. (MANUEL, 1999, p. 7).

A capa ilustrada abaixo é uma das 10 Clandestinas produzidas por Antonio Manuel. Esta, em especial, faz uma contundente acusação às escusas relações da mídia impressa com a ditadura, ao subordinar graficamente uma imagem de autoridades políticas à manchete criada e inserida na página por ele: "Chiqueiro insuportável / Abajo el puerco intelectual." ${ }^{5} \mathrm{~A}$ foto retratava Chagas Freitas (dono do jornal e governador do Rio de Janeiro) oferecendo uma medalha ao general Adalberto Pereira, indicado por Médici à vice-presidência.

3 Trecho do poema intitulado Balada do Esplanada.

4 O artista se infiltrou na tribuna graças a Ivan Chagas Freitas, filho do proprietário do periódico, disponibilizando funcionários para auxiliar Antonio Manuel.

5 Também é possível observar na mesma página, a fotografia de Antonio Manuel com o crítico argentino Romero Brest, que em visita ao Morro do Borel reage indignado à postura da elite intelectual carioca no conchavo com a ditadura e grita Abajo el puerco intelectual - frase que Antonio Manuel aproveita na montagem da manchete. 


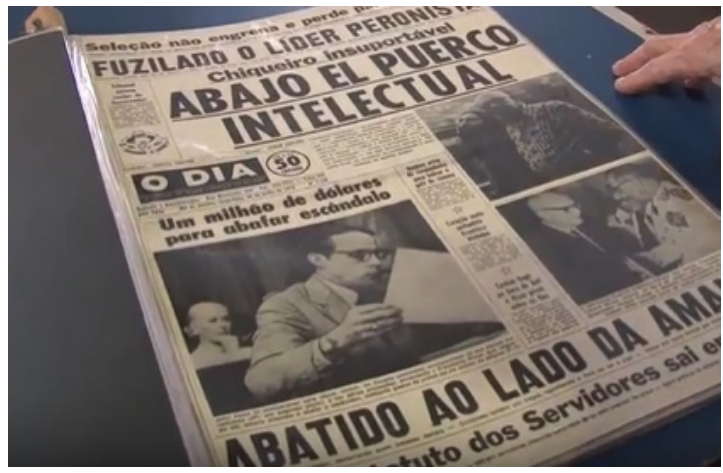

Fig. 3. Clandestinas, 1973. Frame do curta-metragem Antonio Manuel (SESC TV, 2014).

Outras capas abordaram temas relativos à situação das artes no Brasil, satirizaram as notícias e renderam homenagens a amigos mortos (como a Clandestina dedicada a Torquato Neto com a manchete: "Deus um clarão no salão, poeta virou estrela"; ou a dedicada a Ivan Serpa, seu professor e amigo: "Pintor ensina Deus a pintar").

A mimese camaleônica com a diagramação do jornal era quebrada pela estranheza que as notícias fictícias produziam e é nesse embate que aconteceu o ultrapassamento poético da obra: uma quase invisibilidade que se tornava, subitamente, escandalosa.

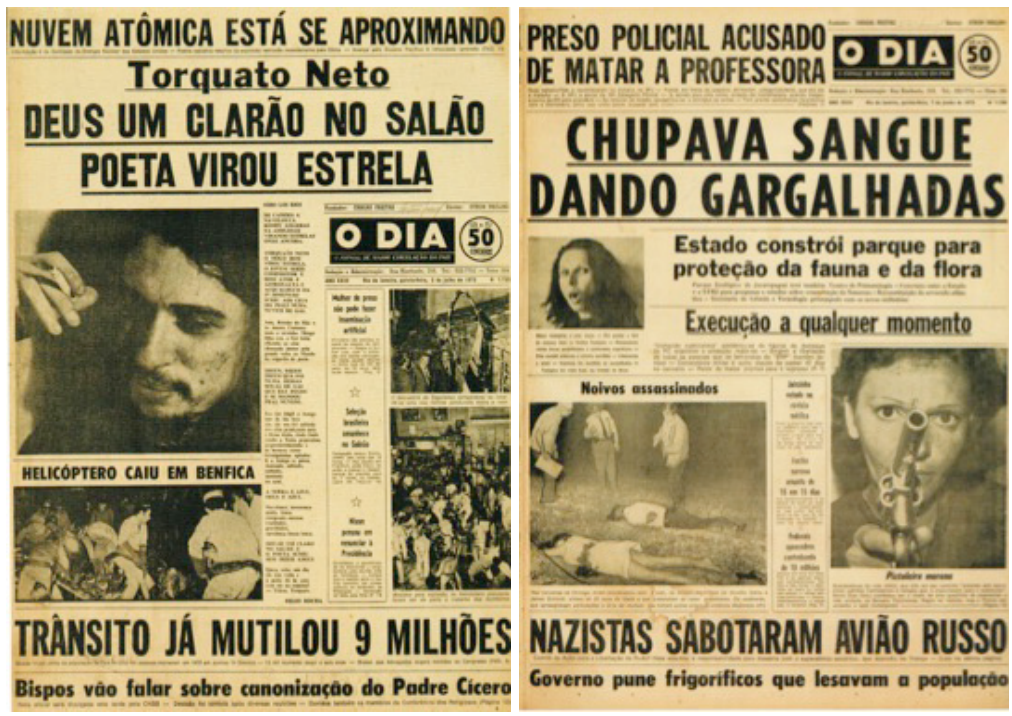

Fig. 4. Clandestinas (1973-1975), acervo do artista. Retiradas do livro I want to act, not to represent!

O ciclo da obra se completava quando os jornais de Antonio Manuel eram deixados nas bancas para serem vendidos com os normais. A metodologia artística do artista, 
além de parasitar o sistema de produção industrial da notícia, se aproveitava do sistema de circulação mercadológica do jornal para fazer circular sua própria poética fora dos circuitos das galerias de arte e museus. Acontecia de qualquer um, por acaso, sair para comprar um jornal e voltar para casa com uma obra de arte. Tal estratégia funcionava como uma poderosa e radical erosão crítico-poética nos circuitos artísticos convencionais, além de provocar, com inteligência, a censura da ditadura.

O nome Clandestinas tem muito a ver com o anonimato do processo criativo: estar invisível nas oficinas do jornal, trabalhar fora do ambiente controlado do ateliê, imiscuir elementos da poética artística para dentro da linguagem tipográfica e incorporar o massivo da indústria da comunicação em seu trabalho, clandestinamente. É claro que a invisibilidade e o anonimato protegeram-no do cerco da ditadura, mas em quase todas as capas de Clandestinas figuravam fotos de Antonio Manuel ou de seus amigos (Hélio Oiticica, Ligia Pape, entre outros). Essa exposição evidenciava o grupo articulador das ações, mas ninguém sabia como eram produzidas, até que Antônio de Pádua Chagas Freitas descobriu a existência de Antonio Manuel em seu jornal. Quando soube, o expulsou.

\section{Folhear Antonio Manuel, De 0 às 24 horas.}

Antonio Manuel provocava criticamente as instituições do sistema das artes (museus e galerias) porque, ao seu ver, estas se igualavam à ditadura ao praticarem uma autocensura, excluindo trabalhos mais experimentais que não se encaixavam no circuito. De 0 às 24 horas foi uma intervenção que contestou a dependência dos artistas em relação aos museus como centralizadores de critérios curatoriais.

Em 1975, o Museu de Arte Moderna do Rio de Janeiro (MAM Rio), assustado com a recorrente interdição de exposições e bienais do país pela polícia militar, desiste de uma exposição de Antonio Manuel quase na véspera da abertura. Todas as obras foram vetadas e, como último recurso para evitar o cancelamento total, o artista propôs uma única obra - um bode vivo no foyer do museu, que deveria ser cuidado e alimentado enquanto durasse a exposição.

Um bode! Era um bode e era o bode da época. Também tinha a coisa toda da "bode" arte... Enfim, ele era o bode geral. Tinha estabelecido com um amigo meu, que era do jornal O Dia, que ele daria uma manchete daquele momento "Deu bode no MAM". (MANUEL apud BUENO, 2010, p. 99).

Com o bode, Antonio Manoel faz referência à sua performance O Corpo É a Obra, na qual se apresentou completamente nu no Salão de Arte Moderna de 1970, oferecendo-se como uma aquisição permanente do museu que deveria ser abrigado e mantido ali, como qualquer outro quadro ou escultura. 


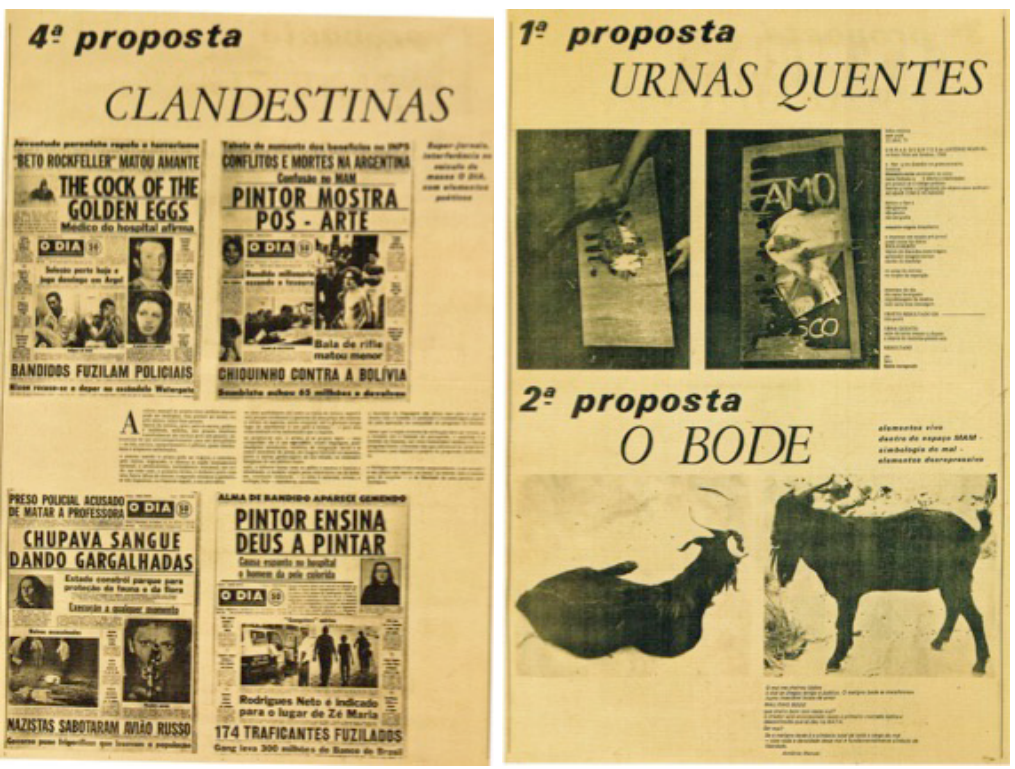

Fig. 5. De 0 às 24 horas (1975). Acervo do artista, retiradas do livro / want to act, not to represent! (2011).

Mas o MAM vetou o bode também. Diante disso, Antonio Manuel decidiu juntar todo o material recusado e elaborar uma resposta crítica ao circuito. É aí que o artista concebe uma expressão totalmente nova, variando entre obra de arte, exposição e jornal, o que torna árdua a tarefa de dar nome e contorno para este trabalho.

O artista encontrou no periódico carioca, O Jornal, o acolhimento para sua ideia - uma exposição-encarte, intitulada Antonio Manuel: De 0 às 24 Horas. Esse caderno deveria entrar em uma edição do periódico como suplemento cultural. Antonio Manuel declarou em entrevista à curadora Ana Maria Maia o que pretendia com De 0 às 24 Horas.

Era uma mostra minha para estar nas bancas e, dessa maneira, romper com sistemas oficiais da arte daquele período. O título sugeria a duração de um dia apenas. Era uma obra descartável, embora pudesse ser guardada. A mostra no jornal cumpre a função de disseminar um ruído de informação de forma relâmpago, com tiragem muito grande, de 60 mil exemplares. Nesse sentido, assemelha-se a ações de guerrilha. (MANUEL, 2015).

Decididamente não seria possível fazer uma exposição nos moldes habituais, já que o espaço proposto era uma página e não uma sala. Ainda que o material selecionado representasse um apanhado de suas obras, como em geral ocorre em mostras de artes plásticas, traduzi-las para a exibição no periódico exigiu que Antonio Manuel recriasse e atualizasse sua poética para o novo formato. Pois bem, o material estético tomado de partida já não era mais o mesmo que seria exibido no museu. 
A elasticidade tradutória do artista transformou De 0 às 24 Horas em algo que pode ser chamado de arte, inaugurando uma forma de fruição da obra. No entanto, a fixidez da ideia de arte não funciona perfeitamente aqui. É mais acertado pensar que De 0 às 24 Horas foi uma intervenção, mais exatamente uma intervenção gráfica.

Materialmente, o que surge da intervenção (ou exposição-obra) é jornal impresso que, como objeto efêmero e banal, arremessa a arte para o limiar do desaparecimento (FREITAS, 2007, p. 182). Antonio Manuel assume, já no título da exposição, a efemeridade de sua obra, além de incorporar a indefinição nominal da exposição-obra-jornal. Além de todos esses deslizamentos de fronteiras entre os sistemas que opera, implanta a experiência tátil-visual, característica própria da leitura do jornal (PINHEIRO, 2013) na substituição da fruição visual da concretude material das obras. O corpo do leitor que lê a exposição no jornal não é o mesmo corpo que vai ao museu: ter a obra nas mãos e folheá-la. "Frente a esse trabalho, creio, não há como simplesmente optar entre vê-lo como uma obra ou lê-lo como um jornal. Aí sua força de sentidos, cumpre entender, seu jogo aberto entre o ver e o ler". (FREITAS, 2007, p. 182).

\section{Conclusão: $o$ jornal se fez cidade}

Certamente uma visada panorâmica sobre os meios de comunicação não distinguirá com facilidade o vozerio polissêmico da cultura latino-americana. O que figura nas primeiras páginas dos jornais impressos são, quase sempre, discursos binarizantes. No entanto, se olharmos atentamente, descobriremos nas margens das páginas de jornal ou até mesmo enquistadas nas mais áridas notícias, as manifestações dirsruptivas dessa ordem. Mas que fique claro que não procuramos o extraordinário ou a grande diferença que nos defina. Parecem mais interessantes as conexões inaugurais, minoritárias, flagradas nas intrusões em vai-e-vem de atravessamentos e dobras de sistemas sobre outros sistemas - da oralidade sobre o texto, do texto sobre a imagem, da poesia sobre a prosa, da rua sobre a dança, da arquitetura sobre a culinária, do popular sobre o erudito etc. - que acabam por dar visibilidade ao que parece ser uma grande vantagem tradutória que a colonização europeia, sem querer, nos trouxe na ponta da chibata.

Foram os jornais o primeiro veículo popular e massivo obrigado a se abastecer, mesmo contra a vontade dos próprios donos, das confluências entre o gráfico e o visual na diagramação espacial da página, dando concretude manual e visível, com periodicidade e exposição públicas, nas moradias e ao ar livre, ao conflito entre civilizações da língua escrita e civilizações do gesto falado, civilizações da razão de um sujeito centrado e civilizações do corpo que dança. (PINHEIRO, 2015, p. 10).

O jornal, como nos explica Amálio Pinheiro, tem especificidades próprias - "é portátil, maleável, tátil às exigências dos dedos e de todo o corpo, obriga o leitor a participar de 
um modo do conhecimento, além do noticiado[...]" (Pinheiro, 2013, p. 61). É do viver urbano, especialmente latino-americano, estar em ambiente externo, sentar-se à mesa de um bar, abrir o jornal, começar uma discussão sobre algum tema quente com desconhecidos.

Gerchman sentou no botequim e enquanto lia o jornal-cidade, Lindonéia-manchete se fazia paisagem. "Esta, não contemplamos mais na natureza, e sim, nas primeiras páginas dos jornais. [...] Tudo se passa nas cidades. Lindonéia seria um pedaço de jornal que seria um pedaço da cidade" (DUARTE, 1998, p. 68).

Antonio Manuel se inscreve margianamente ${ }^{6}$ nas oficinas de prensa para forjar a paisagem com a palavra e com a diagramação. Lygia Pape dispara certeira: "Antonio Manuel trabalha o amor vencido do cotidiano. O jornal. Agora: manchete-dia; invenção remancheteada. [...] O fio-gráfico sempre como alicerce do meio-plástico. Sempre o barulho das rotativas na gênese da informação."7 (PAPE apud DIEGO; CORTES, 2012, p. 595).

A cidade de Gerchman e de Antonio Manuel não é representada literalmente, mas se distribui paisagisticamente no jornal - em sua diagramação, tipos, manchetes, contendo o gestual urbano, que modifica e produz modos de ler. É "[s]aber que o jornal faz convergirem olho e cidade, faz permearem-se corpo e cultura, num espaço de política de lazer e prazer [...]" (PINHEIRO, 2013, p. 61).

Mylène Goudet é professora na faculdade de Arquitetura e Urbanismo e Design de Interiores da Universidade Paulista e doutora em Comunicação e Semiótica pela PUC-SP. Tem mestrado em psicologia clínica.

milagoudet@gmail.com

\section{Referências}

ARAÚJO, V. G. Antonio Manuel e a fotografia - um estudo dos super jornais Clandestinas (1973-1975). Anais do II Encontro de História da Arte. Campinas: IFCH/ Unicamp, 2006. v. 1, p. 550-556. Disponível em: <http://docplayer.com.br/6389027-Antonio-manuel-e-a-fotografia-um-estudo-dos-super-jornaisclandestinas-1973-1975.html $\geq$. Acesso em: 7 jan. 2017.

BUENO, G. (Org.). Antonio Manuel, eis o saldo: textos, depoimentos e entrevistas. Funarte: Rio de Janeiro, 2010.

CALIRMAN, C.; RANGEL, Gabriela. (Orgs.). Antonio Manuel: I want to act, not to represent!. Americas Society/APC: Nova York-São Paulo, 2011.

CAMPOS, H. Ruptura dos gêneros na literatura Latino-Americana. In: MORENO, C. F. (Coord.). América latina em sua literatura. Perspectiva: São Paulo, 1979.

6 A palavra faz referência a série Margianos, de Antonio Manuel - um conjunto de imagens de figuras marginalizadas no universo das notícias, que ele dispunha nas beiradas das páginas, chamando a atenção para o funcionamento das mídias em jogar para escanteio tudo aquilo que não é solvente - travestis, corpos mortos, criminosos detidos etc. Posteriormente ele construiu as Caixas-poemas com estas imagens.

7 Lygia Pape escreveu um texto intitulado $A$ leitura quente de paixão e da morte para a 2a página De 0 às 24 Horas, sob o pseudônimo de Janaína, na qual discorre sobre o trabalho de Antonio Manuel. 
DIEGO, M.; CORTES, D. A pólvora e o estopim: o jornal na obra de Antonio Manuel. Anais do $22^{\circ}$ Encontro ANPAP. Rio de Janeiro: UERJ, 2012. p. 587-597. Disponível em: <http://www.anpap.org.br/anais/2012/pdf/ simposio4/marcelo_diego_e_douglas_cortes.pdf>. Acesso em: 8 jan. 2017.

DUARTE, P. S. Figuras do imperativo urbano [Lindonéia]. In: GERCHMAN, C. (Org.). Rubens Gerchman: o rei do mau gosto. J.J. Carol Editora: São Paulo, 2010.

FONTOURA, A. C. (direção). Video - Ver Ouvir, 1966. Disponível em: <http://www.institutorubensgerchman. org.br/videos/videos.html>. Acesso em: 9 jan. 2017.

FREITAS, A. Contra-arte: vanguarda, conceitualismo e arte de guerrilha-1969-1973. p. 365 Tese de Doutorado em História. Programa de Pós-Graduação em História, Departamento de Ciências Humanas, Letras e Artes. Universidade Federal do Paraná - PPGHIS / SCHLA/UFPR, 2007. Disponível em: <http://livros01. livrosgratis. com.br/cp104502.pdf>. Acesso em: 8 jan. 2017.

GERCHMAN, R. Coleção Portfolio Brasil: Gerchman. J.J. Carol Editora: São Paulo, 2007.

. Encontros. Publicado na Revista E, janeiro 2006, no 104. Disponível em: <https://www.sescsp.org. br/online/artigo/3607_ENCONTROS>. Acesso em: 15 jan. 2017.

LEE-MEDDI, J. Tropicália, o album-manifesto. Disponível em: <http://virtualiaomanifesto.blogspot. com.br/2008/12/tropiclia-ou-panis-et-circencis-o-lbum.html>. Acesso em: 18 Jan. 2017.

LOTMAN, I. M. La Semiosfera I: semiótica de la cultura del texto. Ediciones Catedra S.A: Madrid, 1996.

MANUEL, A. Entrevista a CABO, Sheila et al. Sucessão de fatos. In: BUENO, G. (Org.) Antonio Manuel, eis o saldo: textos, depoimentos e entrevistas. Funarte: Rio de Janeiro, 2010. p. 99-121.

Janeiro, 1999 .

Antonio Manuel: entrevista a Lucia Carneiro e Ileana Pradilla. Editora Lacerda: Rio de

. Exercício experimental da clandestinidade. Entrevista a Ana Maria Maia, 23 nov. 2015. Revista digital Select. Disponível em: <http://www.select.art.br/exercicio-experimental-da-cladestinidade/>. Acesso em: 15 jan. 2017.

MARTíN-BARBERO, J. Ofício de cartógrafo: travessias latino-americanas da comunicação na cultura. Edições Loyola: São Paulo, 2004.

OSÓRIO, C.; MANUEL, A. A política da imagem. Revista Zum, 24 jul. 2014. Disponível em: <http:// revistazum.com.br/revista-zum_6/a-politica-da-imagem/>. Acesso em: 7 jan. 2017.

PEREIRA, B. F. Conceitualismo nas décadas de 60 e 70: Arte, comunicação e política no Brasil e na Argentina. Monografia de Bacharelado em Crítica de Arte - Instituto de Artes Visuais, Universidade Federal do Rio Grande do Sul, 2010. Disponível em: <https://www.lume.ufrgs.br/bitstream/ handle/10183/27980/000768088.pdf?sequence=1 >. Acesso em: 8 jan. 2017.

PINHEIRO, A. América Latina: barroco, cidade, jornal. Intermeios: São Paulo, 2013.

. (Org). O jornal e a cidade: um barroco de viés. Intermeios: São Paulo, 2015.

SANT'ANNA-MULLER, M. R.; MEURER, M. Entre imagem e história - Lindonéia. Fronteiras: Revista Catarinense de História, Florianópolis, n.18, p.105-123, 2010. Disponível em: <http:// www.anpuh-sc.org.br/rev front 18 vers fin/artigo1_lindoneia_mara santana_monike meurer.pdf>. Acesso em: 15 jan. 2017.

VICALDI, Cacá (direção). Antonio Manuel. Vídeo. Curta Artes, SESCTV, 2014. Disponível em: <https:// www.youtube.com/watch?v=MBxw1K95-tw>. Acesso em: 8 jan. 2017.

Rubens Gerchman. Vídeo. Mundo da Arte, SESC TV, s/d. Disponível em: <https://www. youtube.com/watch?v=azXe8FKgzH0>. Acesso em: 8 jan. 2017. 